\title{
Efficiency of mutual fund managers: A slacks-based manager efficiency index
}

\author{
Laura Andreu ${ }^{a}$, Miguel Serrano ${ }^{a}$, Luis Vicente ${ }^{a,}{ }^{*}$ \\ ${ }^{\text {a }}$ Department of Accounting and Finance. University of Zaragoza. Campus Paraíso, 50005 Zaragoza (Spain). \\ * Corresponding author \\ E-mail: \\ landreu@unizar.es (L. Andreu),miguelserranocored@gmail.com (M. Serrano), lavicent@unizar.es (L. Vicente)
}

\begin{abstract}
This paper develops an innovative slacks-based manager efficiency index (SMEI) to evaluate the efficiency of mutual fund managers. First, the SMEI contributes to decisions by evaluating the efficiency of the manager as a whole instead of focusing on individual mutual funds. Second, the SMEI includes socio-demographic variables to extend the mere consideration of financial variables in the model. Third, the SMEI identifies locally efficient but globally inefficient managers. This local SMEI evaluates managers in reference to the 'best practice' competitors with similar management characteristics. Finally, this paper includes a real application of the SMEI in a sample of individual managers in the Spanish mutual fund industry. This empirical illustration further examines the persistence of the efficiency scores and the influence of the SMEI variables on the efficiency of individual managers.
\end{abstract}

EJOR keyword: Investment analysis

Keywords:

Mutual fund managers; Data envelopment analysis; Slacks-based manager efficiency index 


\section{Introduction}

In recent decades, the financial sector has undergone major changes in its activities due to the internationalisation and regulation of financial markets and technological advances, among other factors (Álvarez et al., 2016). These changes have forced financial institutions to transform their business models to survive in this new competition (Kok et al., 2016). This transformation process has implied changes in the efficiency of the financial industry, thereby directing the attention of researchers to different financial sectors and institutions.

Data envelopment analysis (DEA), which was first introduced in Charnes et al. (1978), has been widely used in the efficiency evaluation of the financial industry. Cook and Seiford (2009) and Liu et al. (2013) conduct an exhaustive review of real-world DEA applications, including applications focused on banks, savings banks, loan companies, and the insurance sector. One of the more active applications of DEA in finance is mutual fund performance. The mutual fund literature is mainly focused on these frontier methods because these methods do not require any functional form between return and risk, while the traditional performance measures require this functional form. In addition, the potential use of several inputs and outputs by DEA models is an innovative way to explore mutual fund performance. That is, DEA models help to incorporate additional information that is explicitly used in the decision-making process of mutual fund managers. Therefore, DEA may be considered an alternative approach to traditional performance measures, such as the methods proposed by Sharpe (1966), Jensen (1968), Fama and French (1993) and Carhart (1997). In this sense, Lamb and Tee (2012a) complete the lack of some theoretical foundations in this increasing literature that uses DEA to construct returnrisk ratios for mutual funds.

Murthi et al. (1997) use DEA for the first time to assess mutual fund performance. Their metric, called the DEA portfolio efficiency index (DPEI), can be considered an extension of the widely known Sharpe ratio (Sharpe, 1966) by including the transactional costs as an additional input to the standard deviation of the portfolio returns. In fact, Choi and Murthi (2001) suggest that the Sharpe ratio can be considered a constant return to scale DEA model with the standard deviation of fund returns as a single input and the excess fund returns as a single output. Since then, numerous papers have included extensions and modifications in the set of variables included in the DPEI, but the rationale of the metric remains similar. McMullen and Strong (1998), Premachandra et al. (1998), Morey and Morey (1999), Basso and Funari (2001, 2003, 2017), Galagedera and Silvapulle (2002), Haslem and Scheraga (2003), Chang (2004), Daraio and Simar (2006), Lozano and Gutiérrez (2008) and Lamb and Tee (2012b) are some examples of the increasing DEA literature that evaluates mutual fund performance based on the seminal DPEI of Murthi et al. (1997). Furthermore, Premachandra et al. (2012) and Sánchez-González et al. (2017) apply network DEA models to decompose the efficiency of mutual fund companies. 
These DPEI extensions have also been extended to evaluate hedge funds due to the problems found when using traditional models in the hedge fund world of option-like and nonnormal returns (Fung and Hsieh, 1997; Brealey and Kaplanis, 2001). Gregoriou et al. (2005), Eling (2006) and Kumar et al. (2010), among other scholars, use DEA models to overcome these return-generating problems when assessing hedge fund performance. DEA models also assess pension fund performance (Medeiros, 2010; Andreu et al., 2014) due to the increasing interest in the third pillar of pension schemes as a key factor of the outstanding pension reform, particularly in EU member states (European Union Parliament, 2014).

Although these DPEI extensions contribute to the assessment of portfolio performance, there is a lack of DEA evidence on the efficiency of portfolio managers. That is, although the previous DEA literature mainly focuses on portfolio performance records as a result of the investment decisions made by managers, the efficiency of this decision-making process has been scarcely analysed through DEA models. Thus, the founding DPEI measure should be reformulated to evaluate the efficiency of portfolio managers by including more influential and precise variables in a DEA model that can better identify some specific characteristics of managers. Our paper develops an innovative model to fill this gap in the literature.

As far as we know, only the recent study by Banker et al. (2016) evaluates the efficiency of mutual fund managers using an additive DEA model to evaluate their buying and selling activities relative to the trades of other managers. However, our paper differs from Banker et al. (2016) regarding three main questions, thereby contributing to the literature. First, our model considers the frequent situation of a manager in charge of several mutual funds. Thus, we evaluate the efficiency of the manager as a whole instead of focusing on the results of individual mutual funds. Second, our model includes socio-demographic variables that can influence the decision-making process of mutual fund managers, thereby highlighting that the efficiency of managers is not limited only to a return/risk trade-off. Third, our paper identifies locally efficient managers according to the efficient frontiers formed by competitors with similar attributes as the analysed target managers. This issue is particularly relevant in the mutual fund industries that include managers with varying characteristics. For this purpose, we use the slacks-based model (SBM) proposed by Tone (2001) and its further SBM variations (Tone, 2010).

The implications of our model are relevant in different terms. First, our model is relevant for mutual fund investors to know which managers are more efficient than other managers. Second, our model is also relevant for managers to know their efficiency relative to their industry competitors and to attempt to improve their results. Finally, our model provides relevant information for mutual fund companies to design and implement compensation and promotion systems based on accurate evaluations of their mutual fund managers. These decision 
support systems could improve the efficiency of the remuneration structure of mutual fund companies, thereby increasing the efficiency of the overall mutual fund industry.

We conduct an empirical application in a set of managers of Euro equity mutual funds registered in Spain from January 2009 to December 2016. The choice of this mutual fund industry is justified because the variables included in our model show striking differences in the Spanish market and may play an important role in the evaluation of mutual fund managers. This real-world application also includes the analysis of the main determinants of both a manager's efficiency score and his/her survival as an individual manager in the industry.

This paper is organised as follows. Section 2 describes our slacks-based manager efficiency index (SMEI) and its local variation. Section 3 shows the empirical application to the Spanish mutual fund industry. Section 4 concludes the paper.

\section{The model}

Our model aims to evaluate the efficiency of managers by extending the rationale proposed by the founding DPEI in Murthi et al. (1997). The DPEI measure incorporates transaction costs to modify the basic idea considered in the well-known excess return/risk ratio of Sharpe (1966). The transaction costs are considered in the DPEI by including the expense ratio, portfolio loads and portfolio turnover as additional inputs to the risk that is measured as the standard deviation of the return. The DPEI measure is then formulated according to the DEA approach of Charnes et al. (1978). This model finds the input weights $\left(\omega_{i}, v\right)$ that maximise the ratio of the excess return $\left(E R_{o}\right)$ to the weighted average of the determinants of the transaction costs $\left(x_{i o}, i=1, \ldots, 3\right)$ and the risk $\left(\sigma_{o}\right)$ of the target mutual fund, which is denoted by subscript $o$. This maximisation model is subject to the condition that all such ratios of the analysed $J$ funds are less than or equal to one. The input weights must be higher than or equal to a positive value non-Archimedean infinitesimal $(\varepsilon)$ that is smaller than any positive real number.

$$
\operatorname{Max} D P E I=\frac{E R_{o}}{\sum_{i=1}^{3} \omega_{i} x_{i o}+v \sigma_{o}}
$$

subject to

$$
\frac{E R_{j}}{\sum_{i=1}^{3} \omega_{i} x_{i j}+v \sigma_{j}} \leq 1 \quad \omega_{i}, v \geq \varepsilon \quad j=1, \ldots, J
$$

According to the DPEI, investors should search for efficient mutual funds that maximise the excess return and minimise both the transaction costs and risk. Lozano and Gutiérrez (2008) show that most of the DEA applications to mutual funds use this founding rationale but sophisticate the main variables included in the DPEI. 
Therefore, the challenge in our paper is to adapt the rationale provided by Murthi et al. (1997) to a new model to evaluate managers instead of mutual funds. This issue is particularly relevant because mutual funds can experience manager replacement; therefore, fund performance cannot be attributed to a specific manager (Clare et al., 2014). An analysis at the manager level can properly answer whether some managers are better than other managers. In addition, we emphasise that the DPEI approach does not consider the interaction among the variables of the model in the case of managers who are in charge of several mutual funds. For this purpose, our approach overcomes this shortcoming to evaluate manager efficiency in its entirety rather than the mere assessment of individual mutual funds. This relevant modification to the DPEI must be included in both the inputs and outputs of our new model.

\subsection{The outputs}

According to the previous literature, several measures of return, i.e., gross return, net return, excess return, etc., have been selected as the main output in the majority of DEA applications to financial portfolios (e.g., Choi and Murthi, 2001; Galagedera and Silvapulle, 2002; Chang, 2004; Daraio and Simar, 2006; Andreu et al., 2014; Banker et al., 2016; and Basso and Funari, 2017). In our manager approach, an efficient manager should maximise the returns of all mutual funds of which he/she is in charge. Thus, our model includes the annual gross return of manager $j$ as an output variable $\left(R E T U R N_{j}\right)$. This return is computed as the Total Net Assets (TNA)-weighted sum of the annual gross return obtained by each individual mutual fund within an investment vocation of which manager $j$ is in charge. That is, our model considers that a manager may be in charge of more than one fund and investment vocation in a given year. Then, the annual gross return of each manager within an investment vocation is rescaled following a unity-based normalisation to bring all of the TNA-weighted returns into the range of $[0,1]$. For each investment vocation, this rescaling process subtracts the minimum TNA-weighted return from each manager's TNA-weighted return and divides the result by the difference between the maximum and minimum TNA-weighted return that year. Accordingly, the rescaling process is conducted for each individual manager in each year of the sample period. ${ }^{1}$ This normalisation removes the time effects from the analysis and overcomes the potential negative values of the annual gross returns that are considered by the model. However, the main contribution of this normalisation is to solve the potential bias in the return records of managers who are in charge of several mutual funds with different investment vocations. Sánchez-González et al. (2017) performs a similar unity-based normalisation to consider the different sizes and return patterns of the diverse investment vocations managed by a mutual

\footnotetext{
${ }^{1}$ For an analysis focused on a specific investment vocation, this normalised value should be the excess return of manager $j$ (output $R E T U R N_{j}$ ). For a generalised analysis on a wide range of investment vocations, these normalised values should be weighted by the money managed by manager $j$ in each investment vocation.
} 
fund company. We extend this approach to the different investment vocations that are potentially covered by a manager. That is, the returns weighted by fund size represent to some extent the manager skills, but the different return patterns of the different investment vocations might distort the TNA-weighted returns of a manager. For instance, a manager who specialises in equity funds might obtain upwards-biased TNA-weighted returns in years with bullish stock markets compared with a manager who specialises in bond funds. This annual normalisation provides more consistent TNA-weighted return records across the different investment vocations covered by a manager.

Furthermore, we extend the number of outputs of our model with respect to the only output, i.e., excess return, included in the original DPEI measure. There is extensive literature regarding mutual fund size and performance in DEA applications. For instance, Murthi et al. (1997) find some evidence that larger funds may be more efficient than smaller funds, which may be explained by lower transactions costs. Recently, Basso and Funari (2017) concluded that there is no significant linear correlation between size and performance in a set of European equity mutual funds, but large funds, on average, tend to exhibit a slightly higher performance score than smaller funds, which indicates the presence of scale economies. Thus, the returns obtained by a manager might not be totally independent of the assets under management. Consistent with Sánchez-González et al. (2017), efficient managers should maximise the assets under management to contribute to the operational efficiency of the mutual fund management company. This question is important for the companies where the management fees are largely based on the assets under management instead of performance-based fees. ${ }^{2}$ Specifically, we include the total assets under management by manager $j\left(A U M_{j}\right)$ as the second output of our model.

\subsection{The inputs}

Based on the previously defined outputs, our approach belongs to the models transposed from production theory in combination with some traditional financial performance measures. Accordingly, our new model is consistent with the rationale that an efficient manager maximises the return to the greatest amount of assets under management as possible. However, what is the rationale of the input restrictions against this objective? The answer to this question is relevant to overcome the interpretation problem addressed by Brandouy et al. (2015) when a frontier model combines a traditional financial performance measure and some additional variables. That is, what does the efficiency measure mean in such a setting?

Consistent with the DPEI in Murthi et al. (1997) and according to the literature review of Lozano and Gutiérrez (2008), the most common inputs in DEA applications to mutual funds are the risk and the management costs. These applications frequently use the standard deviation

\footnotetext{
${ }^{2}$ For instance, Díaz-Mendoza et al. (2014) support this finding for the Spanish mutual fund industry.
} 
of returns as a risk input to evaluate the efficiency of mutual funds (e.g., McMullen and Strong, 1998; Basso and Funari, 2001; Choi and Murthi, 2001; Galagedera and Silvapulle, 2002; Basso and Funari, 2003; Chang, 2004; Daraio and Simar, 2006; Premachandra et al., 2012; SánchezGonzález et al., 2017). However, the literature also shows an increasing sophistication in the risk measures by considering the first two or three moments of the portfolio returns, i.e., the variance-covariance matrix and skewness-coskewness matrix. This sophistication has been shown to be particularly relevant in assessing hedge funds (Gregoriou et al., 2005).

However, some researchers have considered risk to be an undesirable output simultaneously produced with return by using directional distance functions and the Luenberger shortage function (e.g., Briec and Kerstens, 2009, 2010; Briec et al., 2004, 2007, 2013; Kerstens et al., 2011). These papers suggest that treatment of risk as an input is unfortunate because risk and return are jointly produced, i.e., risk cannot be anticipated in the return generating process. This assumption should consider risk as an undesirable output rather than an input, similar to the seminal DPEI model and its subsequent literature. This controversy is a relevant issue to determine both the role of risk in our model and the model specification.

Therefore, the selection of risk as an input instead of an undesirable output in our model requires an appropriate justification. This choice is based on the significantly different risk levels associated with the different investment vocations that are potentially covered by a manager. ${ }^{3}$ Furthermore, these differences may even be significant within the same investment vocation, i.e., value equities may show different risk patterns than growth equities in the Eurozone equity investment vocation. Obviously, risk measured as the standard deviation or higher moments of the portfolio returns cannot be exactly observed, but a manager may partly anticipate the level of risk as a consequence of their investment strategies. For instance, investment strategies focused on small capitalisation equities are likely to generate higher levels of risk than investment strategies focused on large capitalisation equities. Thus, the level of risk assumed by the investment strategy of the manager can be anticipated, which supports the literature that claims the choice of risk as an input. ${ }^{4}$ Consequently, our model should consider as an input the overall risk held by a manager in all mutual funds of which he/she is in charge. In addition, our approach should consider the positive effects of portfolio diversification in the manager risk measure, i.e., the risk of a manager cannot be computed as the linear combination of the risk measures of all individual mutual funds for which he/she is in charge. For these reasons, we compute the annual level of risk assumed by manager $j$ each year as the square root

\footnotetext{
${ }^{3}$ Morningstar (2017) supports that small capitalisation equities, large capitalisation equities, international equities, bonds and cash show consistent and significantly different levels of risk across different time horizons from 1970 to 2016.

${ }^{4}$ However, our model specification should consider the particularities where the level of risk cannot be anticipated in such a manner. The next section of this paper includes a complementary approach to our original model that would consider risk as an undesirable output.
} 
of the TNA-weighted sum of the cross products of the annual variances and covariances of the daily gross returns of all mutual funds managed by manager $j$ in a given year $\left(R I S K_{j}\right)$.

Thus, mutual fund investors should pursue managers who provide high returns, assuming a low level of risk. However, there is evidence that the performance of active managers depends largely on their efficiency in timing their buy and sell trades (e.g., Chen et al., 2000). For this reason, portfolio turnover has been included as an input in the DEA literature because it is the main proxy to capture the transaction cost structure in the evaluation of mutual and pension funds (e.g., Murthi, 1997, Choi and Murthi, 2001; Daraio and Simar, 2006; Andreu et al., 2014). The previous literature has shown that managers who trade more often incur higher transaction costs. Specifically, Babalos et al. (2012) conclude that the turnover rate is the main source of inefficiency for their sample funds. Therefore, an efficient manager should incur the lowest transaction costs to obtain the highest return as possible. Annual mutual fund turnover is calculated as the lesser of purchases or sales divided by the average monthly net asset value of the fund (Elton et al., 2010). Similar to the other variables in our model, turnover is TNA-weighted to consider the fact that manager $j$ is in charge of several funds (TURNOVER $R_{j}$.

In addition to transaction costs, it is also relevant to account for the labour costs that companies assume to manage mutual funds. There are very few papers that study the effects of manager compensation on mutual fund performance (e.g., Elton et al., 2003; Golec and Starks, 2004; Agarwal et al., 2009; Ma et al., 2016). These authors find that US managers with performance-based compensation systems exhibit superior performance. However, due to the lack of information on manager compensation for other less-developed mutual fund industries, we incorporate both the education and industry experience of mutual fund managers as a proxy for the manager compensation assumed by mutual fund companies. According to the literature on education among professionals, education is positively related to higher wages and less frequent and shorter periods of unemployment (e.g., Cohen et al., 1997; Riddell and Song, 2011; OECD, 2014; Andreu and Puetz, 2017). Accordingly, it makes sense that the base salary of a mutual fund manager is mainly determined by education and industry experience. ${ }^{5}$

The education-experience input is created through a sigmoid function to combine both the variable education with the variable industry experience of the manager to obtain a nonlinear proxy of labour costs, as this mathematical function has an S-shaped curve. The sigmoid function is widely used in the finance literature as a proxy for learning processes (e.g., Wang and Huang, 2010). In our case, we find this function suitable for variables such as education and experience because the compensation system associated with these variables does not grow linearly. That is, when managers have more (less) industry experience, manager education is

\footnotetext{
${ }^{5}$ The website salary.com confirms this hypothesis for a large sample of US portfolio managers. See more details at http://www1.salary.com/Portfolio-Manager-Salary.html.
} 
less (more) important in the remuneration system. This hypothesis makes sense because high levels of education may signal high job market potential (e.g., Spence, 1973; Weiss, 1983; Hvide, 2003), and these education signals are more important when managers' industry experience is short. Thus, the input education-experience of manager $j$ denoted as $E E_{j}$ is computed in our model as follows:

$$
E E_{j}=\exp _{j}\left(1+e^{-e d u_{j}}\right) \text { when } e d u_{j}=1 ; \quad E E_{j}=\exp _{j} \quad \text { when } e d u_{j}=0
$$

where $\exp _{j}$ is the industry experience of manager $j$, which is computed in years from the first year that Morningstar reports the information for a manager in the database, and $e d u_{j}$ is a binary variable that represents the level of education of manager $j$. This binary variable discriminates between managers with a master's degree $(e d u=1)$ and managers without a master's degree $(e d u=0)$. Therefore, if a manager does not have a master's degree, the variable $E E_{j}$ will take the value of the manager's experience.

\subsection{The slacks-based manager efficiency index (SMEI)}

According to the previously defined input and output variables, an efficient manager should maximise the returns to the greatest assets under management as possible, assuming low levels of risk and transaction and labour costs for the mutual fund company. The rationale of this approach is relevant from the perspective of a management company because it extends the return/risk maximisation problem of mutual fund investors by including both a proxy for the manager remuneration paid by the company and the assets under management as a key determinant of the management fees earned by the company. ${ }^{6}$ Thus, our model aims to assess manager efficiency as a relevant component of a mutual fund company rather than mere individuals (e.g., Premachandra et al., 2012; Sánchez-González et al., 2017). Accordingly, a manager who obtained good return records for a large amount of assets, assuming low levels of risk and transaction costs but more expense in terms of labour costs for the company, could be deemed inefficient if there was a manager who obtained similar returns for the same amount of assets and incurred the same risk and transaction costs but lower labour costs. Thus, our model could be useful to support the manager remuneration systems defined by mutual fund companies.

We extend the DEA formulation of Charnes et al. (1978) in the founding DPEI by integrating the slacks of each input and output individually into an efficiency score. We formulate our new efficiency index following the non-radial SBM proposed by Tone (2001). The SBM is invariant to the units of measurement because the slacks are divided by the level variables so that the units get cancelled, and it monotonically decreases in each input and output

\footnotetext{
${ }^{6}$ The management fees earned by Spanish mutual fund companies are largely based on assets under management instead of performance-based fees. For details, see Díaz-Mendoza et al. (2014).
} 
slack. The SBM is not translation invariant in the case of negative inputs and/or outputs. The SBM approach improves the additive DEA model (Charnes et al., 1985) by providing a slacksbased efficiency score rather than a mere efficiency discrimination.

The general version of the slacks-based manager efficiency index (SMEI) is defined as follows. Let us consider a set of $n$ managers, where each manager $j$ (for $j=1,2,3, \ldots, n$ ) has a set of $m$ inputs $x_{i j}$ (for $i=1, \ldots, m$ ) to produce a set of $s$ outputs $y_{r j}$ (for $r=1, \ldots, s$ ). The SMEI assumes that $x_{i j}>0$ and $y_{r j}>0$. Under the hypothesis of constant returns to scale (CRS) ${ }^{7}, \lambda$ is a nonnegative set of variables $\left(\lambda_{1, \ldots}, \lambda_{n}\right)$ that represent the intensity vector, and $s^{-}$and $s^{+}$are the slack vectors that represent the non-negative sets of input excesses and output shortfalls, respectively. Therefore, the production possibility set $P$ is defined as

$$
P=\left\{(x, y) / \quad x \geq \sum_{j=1}^{n} x_{j} \lambda_{j}, \quad y \leq \sum_{j=1}^{n} y_{j} \lambda_{j}, \quad \lambda_{j} \geq 0\right\}
$$

Considering that $\omega_{i}$ and $\gamma_{r}$ are the weights associated with the i-input and the r-output, respectively, a target manager, denoted by subscript $o$, will be considered efficient in terms of Pareto-Koopmans when it has no input excesses and no output shortfalls for any optimal solution, that is, when $S M E I_{o}=1$ according to the following model:

$$
S M E I_{o}=\min \frac{1-(1 / m) \sum_{i=1}^{m} \omega_{i} s_{i}^{-} / x_{i o}}{1+(1 / s) \sum_{r=1}^{s} \gamma_{r} s_{r}^{+} / y_{r o}}
$$

Subject to

$$
\begin{array}{lll}
\sum_{j=1}^{n} x_{i j} \lambda_{j}+s_{i}^{-}=x_{i o} & \sum_{j=1}^{n} y_{r j} \lambda_{j}-s_{r}^{+}=y_{r o} \quad \sum_{i=1}^{m} \omega_{i}=m \quad \sum_{r=1}^{s} \gamma_{r}=s \\
\lambda_{j}, s_{i}^{-}, s_{r}^{+} \geq 0 & \omega_{\mathrm{i}}, \gamma_{r}>0 \quad \forall j, i, r
\end{array}
$$

According to the previously defined variables in sections 2.1 and 2.2, our empirical application of Eq. (4) has a set of $3 x_{i j}$ inputs (for $i=R I S K$, TURNOVER, EE) to produce a set of $2 y_{r j}$ outputs (for $r=R E T U R N, A U M$ ). In addition, equal weights are considered for inputs and outputs, i.e., $\omega_{i}=1$ and $\gamma_{r}=1$. However, this general model is feasible to consider any weight for inputs and outputs.

\footnotetext{
${ }^{7}$ We assume the CRS hypothesis due to the lack of conclusive results in the DEA literature regarding the presence of either scale economies or scale diseconomies in the mutual funds market (Basso and Funari, 2017). However, the consideration of variable returns to scale (VRS) could be easily included in our model by adding the convexity condition to the intensity vector $\lambda$ as suggested by Tone (2001). Thus, the restriction $\sum_{j=1}^{n} \lambda_{j}=1$ should be included in Eq. (4).
} 
The reference-set $R_{o}$ for the target manager is defined as the set of managers who correspond to positive $\lambda_{j}^{*}$ in the solution of the previous model. Thus, $R_{o}$ are the 'best practice' competitors who serve as a reference for the target manager. ${ }^{8}$

$$
R_{o}=\left\{j / \lambda_{j}^{*}>0, j=1, \ldots, n\right\}
$$

\subsection{The local SMEI}

Tone (2010) finds that the SBM model may fail to identify the 'best practice' competitors who can serve as a reference for the target manager due to the striking differences between the characteristics of the target managers and the characteristics included in the 'best practice' frontier. This limitation may question the accuracy of the SMEI results, particularly in mutual fund industries where managers show varying characteristics. The level of management specialisation is a good example of these differences. For example, the specialist managers who are focused on a unique investment category of mutual funds may not be an adequate 'best practice' reference for a generalist manager focused on a wide range of investment categories, although the specialist managers are in the efficient frontier of the SMEI model.

Tone (2010) proposes four variations of the SBM model. These variants are based on the hyperplanes (facets) instead of the vertices of the efficient frontier obtained by the SBM. These variants allow a new approach to find the most suitable facets with respect to each target manager. Specifically, we follow Variation III to solve the aforementioned problem of nonappropriate reference frontiers. Variation III could be considered a refinement of the general approach of Variation II that evaluates each manager with all possible facets of the reference frontier. Variation III consists of the application of Variation II only to the reference frontiers formed by competitors with similar characteristics to the target manager. According to Tone (2010), Variation III provides more reasonable efficiency scores with less computing effort than Variation II because of the exclusion of reference facets formed by competitors with heterogeneous management characteristics.

Therefore, we define the local SMEI as an innovative approach to find locally efficient managers with respect to competitors with homogeneous characteristics rather than the globally efficient managers obtained by the SMEI (Eq. (4)). The motivation for this new measure is that managers with the same characteristics have the same opportunities to achieve efficiency, thereby ranking managers more comparably and realistically than other models. The main advantage of the local SMEI is the identification of more acceptable reference sets for managers

\footnotetext{
${ }^{8}$ According to the ongoing debate concerning the potential consideration of risk as an undesirable output that is jointly produced with return, our SMEI can be complemented by a non-radial and non-oriented slacks-based model to obtain an efficiency measure in the presence of undesirable outputs. Cooper et al. (2007) address that only non-radial and non-oriented models can capture all aspects of efficiency. Appendix A includes the details of this complementary model that could be easily applied when risk is considered an undesirable output.
} 
because the facets will be formed only by the managers who belong to the same cluster as the target manager. Thus, managers must be classified according to unequivocal and relevant management criteria to obtain mutually exclusive clusters.

Following the SBM Variation III of Tone (2010), our local-SMEI approach minimises the SMEI score from all clustered facets through four steps. First, all managers are classified in $C$ clusters to form homogeneous sets of competitors. Then, we find the set of efficient managers by solving the original SMEI (Eq. (4)). After this, we enumerate all facets and select only maximal friends. This enumeration process is restricted to the facets formed by managers who belong to the same cluster, i.e., managers who can be considered to be real competitors of the target manager according to the clustering process. A subset $P_{j}$ of the CRS-efficient managers in the production possibility set $P$ is defined as a friend if a linear combination of the inputs and outputs of $P_{j}$ is also CRS-efficient. A friend $P_{j}$ is defined as a maximal friend if any addition of the CRS-efficient managers (not in the friends) to $P_{j}$ is not CRS-efficient. ${ }^{9}$ Finally, the local SMEI obtains the efficiency scores (Eq. (6)) for each inefficient manager in reference to each maximal friend facet $R(h)$ that comprise only the efficient managers in the same cluster as the inefficient manager.

$$
\text { Local }-S M E I_{o}^{R(h)}=\max \frac{1-(1 / m) \sum_{i=1}^{m} \omega_{i} s_{i}^{-} / x_{i o}}{1+(1 / s) \sum_{r=1}^{s} \gamma_{r} s_{r}^{+} / y_{r o}}
$$

Subject to

$$
\begin{array}{lll}
\sum_{j \in R(h)} x_{i j} \lambda_{j}+s_{i}^{-}=x_{i o} & \sum_{j \in R(h)} y_{r j} \lambda_{j}-s_{r}^{+}=y_{r o} \quad \sum_{i=1}^{m} \omega_{i}=m & \sum_{r=1}^{s} \gamma_{r}=s \\
\lambda_{j}, s_{i}^{-}, s_{r}^{+} \geq 0 & \omega_{\mathrm{i}}, \gamma_{r}>0 \quad \forall j, i, r
\end{array}
$$

Note that our empirical application of Eq. (6) has a set of 3 equally weighted $x_{i j}$ inputs (for $i=R I S K, T U R N O V E R, E E$ ) to produce a set of 2 equally weighted $y_{r j}$ outputs (for $r=R E T U R N, A U M)$. However, additional variables and unequal weights could be considered in further extensions of this model.

\footnotetext{
${ }^{9}$ See Definitions 5, 6 and 7 (Tone, 2010) for further details of these subsets of facets. The identification of the maximal friends is programmed in an algorithm by Tone (2010), which first obtains the friends. Afterwards, this algorithm deletes the friends who are subsets of other friends (i.e., dominated friends).

Let us illustrate how this algorithm works with the example originally proposed by Tone (2010). Suppose that 4 out of 12 DMUs are efficient. The efficient DMUs are A, B, D and L. Suppose that the set of friends who comprises two DMUs are found to be $[A, D],[B, D],[A, L],[B, L]$ and $[D, L]$. Suppose that the set of friends who comprise three DMUs are $[A, D, L]$ and $[B, D, L]$. According to Tone (2010), the set $[\mathrm{A}, \mathrm{B}, \mathrm{D}, \mathrm{L}]$ cannot be a set of friends. Therefore, the maximal friends are $[\mathrm{A}, \mathrm{D}, \mathrm{L}]$ and $[\mathrm{B}, \mathrm{D}, \mathrm{L}]$ because all the friends who comprise two or less DMUs are subsets of the maximal friends who comprise three DMUs. Furthermore, we can restrict this algorithm to maximal friends who belong to the same cluster as required by our local-SMEI approach. Suppose that A, B, and D are efficient DMUs that belong to cluster 1 , while $L$ is the only efficient DMU that belongs to cluster 2 . Thus, the sets $[A, D]$ and $[B, D]$ are the maximal friends in cluster 1 , and in cluster 2 , we have only one maximal friend facet [L].
} 
The local-SMEI score of each inefficient manager is then obtained as the maximum Local-SMEI ${ }_{o}{ }^{R(h)}$ obtained for all the maximal friend facets $R(h)$. When the local-SMEI finds no feasible solution to the set of maximal friend facets $R(h)$, the target manager is considered to be globally inefficient but locally efficient in relation to the managers with common clustering characteristics.

$$
\text { Local }-S M E I_{o}=\max _{R(h)}\left\{\text { Local }-S M E I_{o}^{R(h)}\right\}
$$

Therefore, the local SMEI is convenient to appropriately identify locally efficient managers who might be misevaluated by the original SMEI if the referent 'best practice' managers show very different characteristics than the target managers.

\section{An empirical application to the Spanish mutual fund industry}

We use a sample of managers from the Spanish mutual fund industry to illustrate how both the SMEI and the local SMEI work in a real-world problem and how these models can be implemented by management companies to define efficiency-based remuneration systems for their managers. We choose this market because Spain is one of the most relevant Euro mutual fund industries with an important concentration from a management perspective, where small and independent management companies coexist with large and bank-owned management companies. ${ }^{10}$ Thus, the heterogeneity of the management units to be analysed emphasises the interest in the results of our SMEI proposal. The initial database consists of 189 mutual funds registered in Spain that invested in Euro equities during our sample period from 2009-2016. This sample is free from survivorship bias because it contains information of both dead and surviving funds over the examined sample period. These mutual funds are managed by both individual managers and management teams. However, our empirical illustration is focused only on the efficiency of individual managers because it is not clear how the different skills of single team members translate into the skills of a management team (Bär et al., 2011). ${ }^{11}$ Thus, the final sample comprises 83 distinct mutual funds and 68 distinct individual managers from January 2009 to December 2016. Every manager in this final sample has single-managed at least one fund for an entire year. There are 57 out of 83 mutual funds that do not change managers in our sample period. Therefore, the accumulated effect of fund efficiency due to previous managers has a minor impact in our study given that the variables are computed on an

\footnotetext{
${ }^{10}$ As of December 2016, Spain was the fifth largest Euro mutual fund industry in terms of the number of funds (Investment Company Institute, 2017). The top 5 and top 10 of the 83 Spanish management companies controlled 58\% and 78\% of the total assets in the industry, respectively (Inverco, 2016).

${ }^{11}$ This analysis is for the purpose of illustration, and the SMEI models can be easily extended to management teams when all the information related to the team is available and to different investment vocations.
} 
annual basis. Thus, it is not necessary to remove the effect of the previous manager when a new manager is appointed. ${ }^{12}$

Mutual fund information is obtained from the Spanish Securities Exchange Commission (CNMV). This dataset includes the return records and the main fund characteristics required in our analysis, such as assets under management, custodial and management fees and the management company of all mutual funds in the sample. Additionally, manager data are obtained from Morningstar Direct. We collect the manager's name, the date on which the manager assumed responsibility for the fund and, in some cases, a brief summary of the manager's career and level of education. This information is complemented by websites such as Citywire or LinkedIn, when available. These websites provide additional information on managers' education, career path, gender, etc.

Table 1 (Panel A) reports the number of managers and mutual funds analysed each year and the distribution of these managers according to their level of specialisation. This sample is not homogeneous in terms of manager specialisation. The percentage of generalist managers, i.e., managers focused on several mutual fund categories, is significantly higher than the percentage of specialist managers, i.e., managers in charge of funds in a given investment category. This issue will be further discussed in the next section of the empirical analysis. Table 1 (Panel B) reports the summary statistics of the inputs and outputs used in the SMEI approach. The large dispersion of these variables also provides evidence of the heterogeneous characteristics of the individual managers included in our sample period.

\subsection{Efficiency assessment using the SMEI model}

First, we apply the SMEI (Eq. (4)) to each individual manager and year to obtain the minimum score associated with the relative maximum slacks of any input and output from the efficient frontier. ${ }^{13}$ Appendix B shows the detailed distribution of these efficiency scores and the reference set for each individual manager during the sample period. Additionally, Appendix $\mathrm{C}$ shows the efficiency ranking of each individual during the sample period. Table 2 (Panel A) displays the descriptive statistics of these efficiency scores for each year and shows that 2009 and 2013 provide the highest levels of efficiency during the sample period. ${ }^{14}$ We apply the nonparametric Kruskal-Wallis test to examine whether the SMEI scores originate from the same distribution. The evidence provided by this test supports that there is a significant difference in the distributions of the SMEI scores across years.

\footnotetext{
${ }^{12}$ Further research could examine the accumulated differential effect of current and previous managers.

${ }^{13}$ The SMEI model has also been computed under the hypothesis of variable returns to scale. We find a rank correlation between the constant and variable returns to scale assumptions greater than $90 \%$. The details are not shown for the sake of brevity, but they are available upon request.

${ }^{14}$ As a robustness check, we examine the correlation between our SMEI scores and the traditional performance measure proposed by Sharpe (1996). The rank correlation of both measures is above 23\%, thereby supporting the differential effect of our SMEI model.
} 


\section{Table 1. Description of the sample and variables in the model}

This table summarises the managers' characteristics and the variables included in the sample from January 2009 to December 2016 . Panel A reports the number of managers and mutual funds analysed each year and the distribution of these managers according to the level of specialisation. Panel B reports the summary statistics of the inputsoutputs used in our SMEI model. Specifically, it reports the median and the standard deviation of the normalised value of the weighted annual gross return (Output RETURN), the annual assets under management in thousand $€$ (Output AUM), the weighted annual total risk assumed by the manager (Input RISK), the weighted annual manager turnover (Input TURNOVER) and the education-experience variable (Input $E E$ ).

\begin{tabular}{|c|c|c|c|c|c|c|c|c|c|c|c|c|c|c|c|c|}
\hline$\underline{\text { Panel A }}$ & \multicolumn{2}{|c|}{2009} & \multicolumn{2}{|c|}{2010} & \multicolumn{2}{|c|}{2011} & \multicolumn{2}{|c|}{2012} & \multicolumn{2}{|c|}{2013} & \multicolumn{2}{|c|}{2014} & \multicolumn{2}{|c|}{2015} & \multicolumn{2}{|c|}{2016} \\
\hline Mutual Funds & \multicolumn{2}{|c|}{37} & \multicolumn{2}{|c|}{56} & \multicolumn{2}{|c|}{56} & \multicolumn{2}{|c|}{40} & \multicolumn{2}{|c|}{43} & \multicolumn{2}{|c|}{47} & \multicolumn{2}{|c|}{43} & \multicolumn{2}{|c|}{48} \\
\hline Managers & \multicolumn{2}{|c|}{30} & \multicolumn{2}{|c|}{41} & \multicolumn{2}{|c|}{40} & \multicolumn{2}{|c|}{32} & \multicolumn{2}{|c|}{34} & \multicolumn{2}{|c|}{36} & \multicolumn{2}{|c|}{35} & \multicolumn{2}{|c|}{39} \\
\hline Specialists & \multicolumn{2}{|c|}{10 (33.33\%) } & \multicolumn{2}{|c|}{12 (29.27\%) } & \multicolumn{2}{|c|}{13 (32.50\%) } & \multicolumn{2}{|c|}{10 (31.25\%) } & \multicolumn{2}{|c|}{11 (32.35\%) } & \multicolumn{2}{|c|}{12 (33.33\%) } & \multicolumn{2}{|c|}{12 (34.29\%) } & \multicolumn{2}{|c|}{17 (43.59\%) } \\
\hline Generalists & \multicolumn{2}{|c|}{$20(66.67 \%)$} & \multicolumn{2}{|c|}{29 (70.73\%) } & $27(67$. & $0 \%)$ & $22(68$ & $75 \%)$ & $23(6$ & $7.65 \%)$ & $24(6$ & $5.67 \%)$ & $23(6$ & $5.71 \%)$ & $22(5$ & $6.41 \%)$ \\
\hline Panel B & Median & St. Dev & Median & St. Dev & Median & St. Dev & Median & St. Dev & Median & St. Dev & Median & St. Dev & Median & St. Dev & Median & St. Dev \\
\hline OUTPUTS & & & & & & & & & & & & & & & & \\
\hline RETURN & 0.6021 & 0.2027 & 0.3570 & 0.2885 & 0.6745 & 0.2172 & 0.3758 & 0.2445 & 0.2665 & 0.1639 & 0.6714 & 0.2205 & 0.4030 & 0.2741 & 0.3530 & 0.1896 \\
\hline$A U M$ & 36,952 & 71,410 & 21,138 & 70,876 & 18,239 & 61,228 & 20,927 & 51,792 & 48,219 & 128,111 & 70,007 & 111,091 & 87,857 & 207,765 & 50,943 & 213,607 \\
\hline INPUTS & & & & & & & & & & & & & & & & \\
\hline RISK & 0.0123 & 0.0060 & 0.0136 & 0.0075 & 0.0148 & 0.0076 & 0.0128 & 0.0065 & 0.0095 & 0.0048 & 0.0098 & 0.0052 & 0.0119 & 0.0052 & 0.0131 & 0.0063 \\
\hline TURNOVER & 0.4071 & 0.2828 & 0.3896 & 0.3302 & 0.4081 & 0.2618 & 0.4361 & 0.3178 & 0.3472 & 0.2703 & 0.1802 & 0.1853 & 0.2200 & 1.0714 & 0.2700 & 0.8860 \\
\hline$E E$ & 6.2035 & 5.4161 & 4.0027 & 5.6537 & 5.2243 & 5.6974 & 5.0350 & 6.0334 & 6.5129 & 5.9531 & 7.0105 & 6.1617 & 8.3417 & 6.2032 & 9.0055 & 6.0079 \\
\hline
\end{tabular}


The complementary extension of the SMEI that uses risk as an undesirable output (see Appendix A) provides results similar to our original SMEI model. ${ }^{15}$

Table 2 (Panel B) displays the most frequent role model manager found each year. According to the definition of these frontiers (Eq. (5)), all the members of these sets are efficient, and they are considered to be the 'best practice' competitors who serve as role models for each evaluated manager. This information is quite relevant because it provides a plan for the 'best practice' managers to follow to gain efficiency. We find that manager 7 is the most frequently identified role model in 4 years out of our 8-year sample period and is a member of the reference set in another year, too. Note that this 'star' manager is a woman with a Business Administration degree but without a master's degree. She is a "senior" manager with several years of experience in the Spanish mutual fund industry and works as a generalist manager who is simultaneously in charge of several mutual funds of different investment vocations.

\section{Table 2. Summary statistics for the SMEI model}

Panel A shows the summary statistics resulting from the SMEI model each year. Panel B shows both the components of the most frequent reference frontier each year and its frequency from the total number of managers analysed each year.

\begin{tabular}{lcccccccc}
\hline Panel A: SMEI scores & $\mathbf{2 0 0 9}$ & $\mathbf{2 0 1 0}$ & $\mathbf{2 0 1 1}$ & $\mathbf{2 0 1 2}$ & $\mathbf{2 0 1 3}$ & $\mathbf{2 0 1 4}$ & $\mathbf{2 0 1 5}$ & $\mathbf{2 0 1 6}$ \\
\hline Number of efficient managers & 9 & 6 & 4 & 6 & 11 & 9 & 9 & 8 \\
Number of managers & 30 & 41 & 40 & 32 & 34 & 36 & 35 & 39 \\
\% of efficient managers & 30.00 & 14.63 & 10.00 & 18.75 & 32.35 & 25.00 & 25.71 & 20.51 \\
SMEI_mean & 0.44 & 0.20 & 0.17 & 0.24 & 0.41 & 0.39 & 0.35 & 0.30 \\
SMEI_median & 0.23 & 0.06 & 0.05 & 0.06 & 0.13 & 0.26 & 0.12 & 0.13 \\
SMEI_standard deviation & 0.40 & 0.34 & 0.29 & 0.38 & 0.43 & 0.38 & 0.42 & 0.38 \\
SMEI_interquartile range & 0.91 & 0.11 & 0.10 & 0.13 & 0.93 & 0.55 & 0.87 & 0.39 \\
Kruskal Wallis test (p value) & & & $28.54(1.8 \mathrm{exp}-04)$ & & & & \\
\hline Panel B: Most frequent reference frontier & & & & & & & & \\
\hline Manager IDs in the frontier & 39 & 7 & 7 & 7 & $7-35$ & 7 & 39 & 39 \\
Frequency/Total number of managers & $5 / 30$ & $26 / 41$ & $36 / 40$ & $21 / 32$ & $9 / 34$ & $18 / 36$ & $11 / 35$ & $11 / 39$ \\
\hline
\end{tabular}

The dynamics of the efficiency scores obtained from the SMEI model is worth our interest. Although the research on efficiency persistence in mutual funds has been vast since the first evidence of Grinblatt and Titman (1992), little attention has been paid to managers' persistence (Pojarliev and Levich, 2010), although this analysis should shed light on the

\footnotetext{
${ }^{15}$ The efficiency rankings between the SMEI model and the SMEI with undesirable outputs (Eq. (A1)) are significantly correlated and show an average Spearman rank coefficient higher than $89 \%$. This correlation is quite similar to the correlation obtained between the SMEI model and the undesirable and non-separable approach (Eq. (A3)). Furthermore, we obtain robust results for a set of 100,000 simulated samples of managers for each year of our sample period. The average Spearman rank coefficient is higher than 95\% between the SMEI and both models included in Appendix A. Thus, the consideration of risk as an input or an undesirable output is not relevant in terms of the empirical results obtained by our SMEI model. The details regarding both the SMEI with undesirable outputs and the simulation process are available upon request.
} 
predictability of managers' efficiency based on the previous SMEI results. Table 3 shows the transition probabilities of both efficient and inefficient managers. Overall, we find evidence of clear persistent patterns in the SMEI scores, particularly for inefficient managers. That is, inefficient managers in year $t-1$ are likely to remain inefficient in the subsequent year. However, the transition probabilities show a striking result when we consider the managers who disappeared from our sample, i.e., they are excluded from the industry or they are members of a management team rather than individual managers. Table 3 does not clearly show that more efficient managers are more likely to persist in our sample than inefficient managers. Thus, are there any different patterns between the individual managers who survive during the entire period and the individual managers who disappeared from our sample? Table 4 further examines this question by analysing the SMEI scores and the variables of the model split by managers’ survivorship in our sample period.

\section{Table 3. Transition probabilities of managers}

Panel A shows the probability of an efficient manager transitioning from a maximum SMEI score in year $t-1$ to both an efficient or inefficient SMEI score in year $t$. This panel also presents the probability of an efficient manager in year $t-1$ not working as an individual manager in year $t$ (disappearing manager). Panel B reports the same transition probabilities for inefficient managers.

\begin{tabular}{|c|c|c|c|c|c|c|c|}
\hline \multicolumn{8}{|c|}{ Panel A: Transition probabilities for efficient managers } \\
\hline & 2009-2010 & 2010-2011 & 2011-2012 & 2012-2013 & 2013-2014 & 2014-2015 & 2015-2016 \\
\hline Efficient $t-1 \rightarrow$ Efficient $_{t}$ & $22.2 \%$ & $66.7 \%$ & $50.0 \%$ & $66.7 \%$ & $54.5 \%$ & $44.5 \%$ & $55.6 \%$ \\
\hline Efficient $t-1 \rightarrow$ Inefficient $t$ & $77.8 \%$ & $33.3 \%$ & $0.0 \%$ & $16.6 \%$ & $36.4 \%$ & $33.3 \%$ & $44.4 \%$ \\
\hline Efficient $_{t-1} \rightarrow$ Disappearing $t$ & $0.0 \%$ & $0.0 \%$ & $50.0 \%$ & $16.6 \%$ & $9.1 \%$ & $22.2 \%$ & $0.0 \%$ \\
\hline \multicolumn{8}{|c|}{ Panel B: Transition probabilities for inefficient managers } \\
\hline Inefficient $t-1 \rightarrow$ Efficient $t$ & $4.7 \%$ & $0.0 \%$ & $5.6 \%$ & $15.4 \%$ & $4.3 \%$ & $7.4 \%$ & $7.7 \%$ \\
\hline Inefficient $t-1 \rightarrow$ Inefficient $t$ & $85.8 \%$ & $94.3 \%$ & $69.4 \%$ & $76.9 \%$ & $91.3 \%$ & $59.3 \%$ & $84.6 \%$ \\
\hline${\text { Inefficient } t-1 \rightarrow \text { Disappearing }_{t}}$ & $9.5 \%$ & $5.7 \%$ & $25.0 \%$ & $7.7 \%$ & $4.4 \%$ & $33.3 \%$ & $7.7 \%$ \\
\hline
\end{tabular}

The non-parametric Mann-Whitney test that applied to the SMEI scores provided in Table 4 does not reject the null hypothesis that for the entire period, the SMEI scores of managers and the remaining managers come from identical populations, i.e., efficiency seems to be significantly irrelevant in determining the survivorship of an individual manager across the entire sample period in the Spanish industry, thereby strengthening the previous evidence reported in Table 3. To deepen the understanding of this issue, we also apply the Mann-Whitney test to the set of inputs and outputs of the model. The results of this non-parametric test of the SMEI variables support that both the assets under management and the education-experience of managers are the only variables that may significantly determine the survivorship of an individual manager. More assets and education-experience help managers to keep their jobs as individual managers. In contrast, returns, risk and turnover for the entire period are not significantly different between managers and the remaining managers. 


\section{Table 4. SMEI scores and variables divided by managers' survivorship}

This table shows the mean of the SMEI scores and SMEI variables (inputs and outputs) across the entire sample period for the individual managers who survived all the years of our sample period (entire period managers) and the managers who did not remain individual managers during the entire sample period (remaining managers).

\begin{tabular}{lcccccc}
\hline & SMEI score & RETURN & AUM & RISK & TURNOVER & EE \\
\hline Entire-period Managers & 0.267 & 0.471 & 111,185 & 0.010 & 0.509 & 10.95 \\
Remaining Managers & 0.327 & 0.483 & 60,488 & 0.010 & 0.402 & 6.12 \\
Mann-Whitney test (p value) & $9,842(0.628)$ & $9,609(0.891)$ & $6,649(0.000)$ & $9,741(0.739)$ & $8,417(0.104)$ & $4,242(0.000)$ \\
\hline
\end{tabular}

\subsection{Locally efficient managers}

We create two clusters in our sample to illustrate how the local SMEI (Eq. (7)) works in a real-world problem. We choose the manager's level of specialisation to form these clusters. Specifically, we calculate the number of funds managed by each individual manager each year. Then, we compute the number of investment vocations in which the manager is working each year. If all the mutual funds correspond to a single investment vocation, this manager is considered a specialist. Otherwise, the manager is considered a generalist. Our choice of these clusters is justified by the recent evidence that supports the relevance of managers' specialisation for management companies to optimally allocate managers. Fang et al. (2014) address that companies assign managers to market segments depending on their management skills. Zambrana and Zapatero (2017) also find that it is optimal to allocate managers with market timing skills to generalist responsibilities and managers with stock-picking skills to specialist duties.

Table 5 reports both the number of managers included in each cluster and the number of efficient managers that result from the SMEI model according to the previously defined level of specialisation. Overall, Table 5 shows that the percentage of efficient managers included in the cluster specialist $(S)$ is mostly higher than the percentage of efficient managers in the cluster generalist $(G)$ for the entire sample period.

\section{Table 5. Clusters based on the manager's level of specialisation}

This table shows the number of SMEI-efficient managers each year according to the manager's specialisation. The number of managers included in the cluster specialist $(S)$ and in the cluster generalist $(G)$ is denoted in parentheses.

\begin{tabular}{lcccccccc}
\hline & $\mathbf{2 0 0 9}$ & $\mathbf{2 0 1 0}$ & $\mathbf{2 0 1 1}$ & $\mathbf{2 0 1 2}$ & $\mathbf{2 0 1 3}$ & $\mathbf{2 0 1 4}$ & $\mathbf{2 0 1 5}$ & $\mathbf{2 0 1 6}$ \\
\hline SMEI-efficient specialists (Cluster S) & $5(10)$ & $2(12)$ & $1(13)$ & $3(10)$ & $5(11)$ & $3(12)$ & $5(12)$ & $4(17)$ \\
SMEI-efficient generalists (Cluster G) & $4(20)$ & $4(29)$ & $3(27)$ & $3(22)$ & $6(23)$ & $6(24)$ & $4(23)$ & $4(22)$ \\
\hline
\end{tabular}


As outlined in section 2.4, all the combinations of both efficient generalist and specialised managers within each cluster and for each year should be enumerated. Table 6 shows the number of facets, friends' facets and maximal friends' facets for the two clusters $S$ and $G$ in our sample period. Note that the clusters with the greatest number of facets are the clusters of generalist managers in 2013 and 2014, with 63 total facets. This set of facets enables us to enumerate 27 and 23 friends in the generalist cluster, respectively, to finally obtain 3 maximal friends, which are not dominated by any other set of friends. ${ }^{16}$

\section{Table 6. Facets, friends and maximal friends per cluster and year}

This table summarises the total number of facets, friends' facets and maximal friends' facets obtained from the clustering process depending on the manager's level of specialisation.

\begin{tabular}{|c|c|c|c|c|c|c|c|c|}
\hline $\begin{array}{l}\text { Panel A } \\
\text { Specialist Managers (S) }\end{array}$ & 2009 & 2010 & 2011 & 2012 & 2013 & 2014 & 2015 & 2016 \\
\hline Number of Facets & 31 & 3 & 1 & 7 & 31 & 7 & 31 & 15 \\
\hline Number of Friends & 19 & 3 & 1 & 4 & 9 & 4 & 17 & 10 \\
\hline Number of Maximal friends & 2 & 1 & 1 & 2 & 4 & 2 & 2 & 2 \\
\hline \multicolumn{9}{|l|}{$\begin{array}{l}\text { Panel B } \\
\text { Generalist Managers }(G)\end{array}$} \\
\hline Number of Facets & 15 & 15 & 7 & 7 & 63 & 63 & 15 & 15 \\
\hline Number of Friends & 6 & 9 & 4 & 7 & 27 & 23 & 4 & 9 \\
\hline Number of Maximal friends & 3 & 2 & 2 & 1 & 3 & 3 & 4 & 2 \\
\hline
\end{tabular}

The results of the local-SMEI model conducted to evaluate managers' efficiency according to their level of specialisation are reported in Table 7. Specifically, Panel A shows the distribution of the local-SMEI efficiency scores (Eq. (7)) for specialist managers, and Panel B shows the corresponding scores for generalist managers. When the local-SMEI model finds no feasible solution to the set of maximal friends within the same cluster, the target manager is considered to be globally inefficient but locally efficient in relation to the managers with common clustering characteristics, namely, specialist and generalist, in this case.

According to Tone (2010), one of the main merits of this variation is that the efficiency score is obtained in reference to the efficient competitors in the same cluster. Thus, the results are more acceptable and understandable. However, Tone (2010) also concludes that applications to real-world problems are necessary to check for the consistency of the SBM variations. Our paper contributes to this enquiry with a real application to mutual fund markets.

Table 7 shows some interesting findings to consider regarding this issue. First, because of the construction of the local-SMEI model, we find that this variation improves the efficiency results obtained by the SMEI model in the previous section. This finding was already

\footnotetext{
${ }^{16}$ Tone (2010) emphasises that SBM Variation III is a relevant contribution to reduce the computational resources required for large-scale problems involving a massive enumeration of facets.
} 
considered theoretically by Tone (2010), and it accords with the definition of more appropriate reference frontiers within the same cluster that help in the identification of locally efficient managers. However, Table 7 finds a striking result in 2011 because all specialist managers are considered locally efficient. Note that there is only one globally efficient manager in this cluster. Thus, this result casts doubt on the general application of this variation.

Let us focus on 2011 to deepen our understanding of this problem. Only 1 of the 4 globally efficient managers that were found in 2011 by the SMEI model was a specialist, i.e., manager ID 1. Thus, according to this globally efficient specialist, there was only one facet formed by this manager, and this one-manager facet was the only friend and maximal friend to act as the reference frontier for the remaining specialist managers in the application of the localSMEI. The problem arises when the local-SMEI finds no feasible solution to this sole manager maximal friend frontier.

Furthermore, the analysis of the average SMEI scores based on the global frontier (Appendix B) of the locally efficient managers reported in Table 7 can reveal which group of managers, i.e., specialists or generalists, are adversely affected the most by using the global frontier. In our empirical illustration, we find that locally efficient specialist managers decrease their efficiency scores the most when using the global reference frontier. ${ }^{17}$ This result would especially justify the use of the local SMEI model in the specialist cluster to obtain accurate results considering homogeneous reference competitors.

According to Tone (2010), Table 7 provides more acceptable results in terms of the evaluation of the efficiency of managers with similar characteristics because these results are obtained in reference to the efficient managers in the same cluster. In addition, the sample split divided into different clusters helps to reduce excessive enumeration of maximal friends required by this model. However, our empirical application finds that this variation may fail to properly evaluate efficiency for small clusters with only one globally efficient manager. Alternatives such as picking the globally efficient managers in the adjacent clusters to form the maximal friends (Tone, 2010) are not appropriate when there are only two excluding clusters, i.e., specialists $(S)$ and generalists $(G)$.

\footnotetext{
${ }^{17}$ Locally efficient managers in the specialist cluster obtain an average SMEI $=0.186$ per year based on the global frontier, while locally efficient managers in the generalist cluster obtain a yearly average SMEI $=0.219$.
} 


\section{Table 7. Managers' efficiency depending on their level of specialisation}

This table shows the distribution of the local-SMEI efficiency scores according to their level of specialisation. Managers are classified as specialists into cluster $S$ if they manage mutual funds on just one investment objective, while managers are classified as generalists into cluster $G$ if they manage mutual funds with several investment objectives. Panel A shows the distribution of the local-SMEI efficiency scores for specialist managers, and Panel B shows the corresponding local-efficiency scores for generalist managers. When this model finds no feasible solution to the maximal friends within the same cluster, the target manager is considered to be globally inefficient but locally efficient in relation to the managers with common clustering characteristics - in this case, specialists and generalists.

* shows Manager IDs who were considered Specialists in some years and Generalists in other years.

\begin{tabular}{|c|c|c|c|c|c|c|c|c|c|}
\hline \multicolumn{10}{|l|}{ Panel A } \\
\hline 1 & & Loc. Effic & 1 & 1 & 1 & 1 & 1 & \multirow[b]{2}{*}{0.126} & \multirow[b]{2}{*}{0.186} \\
\hline $4 *$ & & & & & & & & & \\
\hline 6 & \multirow{3}{*}{\multicolumn{2}{|c|}{0.640}} & & & 0.272 & 0.116 & \multicolumn{2}{|l|}{1 Loc. Effic } & \multirow[b]{2}{*}{0.001} \\
\hline 8 & & & 0.283 & 1 Loc. Effic & 0.255 & 5.6exp-05 & 2.1exp-05 & 0.001 & \\
\hline 9 & & & 1 Loc. Effic & 1 Loc. Effic & 1 Loc. Effic & 0.217 & 1 Loc. Effic & 0.143 & 0.067 \\
\hline 10 & & Loc. Effic & 0.397 & 1 Loc. Effic & 0.317 & 1 Loc. Effic & 1 Loc. Effic & 0.147 & 1 Loc. Effic \\
\hline 11 & & 1 & 0.109 & 1 Loc. Effic & & & & & \\
\hline 14 & & 1 & 1 Loc. Effic & 1 Loc. Effic & 1 Loc. Effic & 1 & 1 Loc. Effic & 0.521 & 0.406 \\
\hline 17 & & & 0.226 & 1 Loc. Effic & 0.278 & & & & \\
\hline 20 & & 0.092 & 0.106 & 1 Loc. Effic & & & & & \\
\hline 25 & & 1 & 1 Loc. Effic & 1 Loc. Effic & & & & & \\
\hline $29 *$ & & & & & & & & 1 & 1 \\
\hline $33 *$ & & & & & & & & & 0.139 \\
\hline 34 & & & & & & & 1 Loc. Effic & & \\
\hline 35 & & Loc. Effic & 1 Loc. Effic & 1 Loc. Effic & & 1 & & & \\
\hline 37 & & & & & & & 1 & 1 & 0.603 \\
\hline 39 & & 1 & 1 & 1 Loc. Effic & 1 & 1 & 1 & 1 & 1 \\
\hline 41 & & & & & 1 & 1 & 0.337 & & \\
\hline 42 & & 1 & 1 Loc. Effic & 1 Loc. Effic & & & & & \\
\hline 43 & & & & & & 0.420 & 0.183 & & \\
\hline 45 & & & & 1 Loc. Effic & 1 Loc. Effic & 1 Loc. Effic & 1 Loc. Effic & & \\
\hline 55 & & & & & & & & 0.207 & 0.111 \\
\hline 56 & & & & & & & & 1 & 1 \\
\hline 58 & & & & & & & & 1 & 0.447 \\
\hline 62 & & & & & & & & 0.172 & 0.239 \\
\hline 64 & & & & & & & & & 0.128 \\
\hline 65 & & & & & & & & & 0.174 \\
\hline 67 & & & & & & & & & 0.175 \\
\hline 68 & & & & & & & & & 1 \\
\hline Mean Cluster & & 0.873 & 0.677 & 1.0000 & 0.712 & 0.705 & 0.793 & 0.526 & 0.502 \\
\hline St. Dev. Cluste & $r(S)$ & 0.297 & 0.406 & 0.000 & 0.372 & 0.421 & 0.381 & 0.434 & 0.409 \\
\hline
\end{tabular}


Table 7 (Continued)

\begin{tabular}{|c|c|c|c|c|c|c|c|c|c|}
\hline \\
\hline $\begin{array}{l}\text { Panel B } \\
\text { Generalists }(G)\end{array}$ & \multicolumn{2}{|r|}{2009} & 2010 & 2011 & 2012 & 2013 & 2014 & \multirow[t]{2}{*}{2015} & \multirow[t]{2}{*}{2016} \\
\hline 2 & & 1 & 1 & 1 & & & & & \\
\hline 3 & & 0.386 & 0.320 & 0.316 & & 0.593 & 0.537 & 0.213 & 0.239 \\
\hline $4^{*}$ & & 1 & 0.420 & 0.404 & 0.447 & 0.646 & 0.595 & & \\
\hline 5 & & 1 & 1 Loc. Effic & 0.132 & & & & & \\
\hline 7 & & & 1 & 1 & 1 & 1 & 1 & 1 Loc. Effic & 1 \\
\hline 12 & & 0.225 & 0.098 & 0.130 & 0.129 & 1 Loc. Effic & 0.534 & 1 & 1 \\
\hline 13 & & 0.368 & 0.298 & 0.413 & 0.360 & 0.525 & 0.702 & 1 Loc. Effic & 0.514 \\
\hline 15 & $1 \mathrm{Loc}$ & oc. Effic & 0.303 & 0.431 & 0.276 & 0.453 & 0.382 & & \\
\hline 16 & & & 0.504 & 0.290 & 0.041 & 1 Loc. Effic & 0.696 & 1 Loc. Effic & 0.554 \\
\hline 18 & & 0.193 & 0.292 & 0.507 & 0.246 & 0.505 & 0.286 & 0.199 & 1 Loc. Effic \\
\hline 19 & $1 \mathrm{Loc}$ & oc. Effic & 2.2exp-04 & 0.145 & 0.310 & 0.716 & 0.476 & 1 Loc. Effic & 1 Loc. Effic \\
\hline 21 & $1 \mathrm{Loc}$ & oc. Effic & 0.670 & & & & & & \\
\hline 22 & & & 0.448 & 0.333 & 0.229 & 1 & 0.923 & & \\
\hline 23 & & & & & & & 1 & 1 Loc. Effic & 1 Loc. Effic \\
\hline 24 & & & 0.291 & & & & & & \\
\hline 26 & & 0.509 & 0.333 & 0.115 & & & & & \\
\hline 27 & & & 0.133 & 0.120 & 0.129 & 1 & 1 & 1 & 1 \\
\hline 28 & & 0.247 & 0.240 & 0.201 & 0.433 & 0.684 & 0.482 & 0.287 & 0.339 \\
\hline $29 *$ & & 0.353 & 0.664 & 0.398 & 0.517 & 1 & 1 & & \\
\hline 30 & & & & & & 1 & 1 & 0.099 & \\
\hline 31 & & 0.070 & 0.050 & 0.124 & 0.373 & 0.736 & 1 & & \\
\hline 32 & $1 \mathrm{Loc}$ & oc. Effic & 0.362 & 0.557 & 0.388 & 0.339 & 0.427 & & \\
\hline $33 *$ & $1 \mathrm{Loc}$ & oc. Effic & & & & & & & \\
\hline 36 & & & 0.659 & 1.2еxp-04 & 1 & & & & \\
\hline 38 & & & & & & & 1 Loc. Effic & & \\
\hline 40 & & 8еxp-05 & & & & & & & \\
\hline 44 & & & 0.732 & 0.617 & 0.321 & & & & \\
\hline 46 & & & & & 1 & 0.687 & 0.530 & 1 Loc. Effic & 1 Loc. Effic \\
\hline 47 & & & 0.510 & 0.457 & 0.223 & 0.175 & 0.088 & 0.085 & 1 Loc. Effic \\
\hline 48 & & & 1 & 1 & & & & & \\
\hline 49 & & & 1 & 0.081 & 0.161 & 0.432 & 0.461 & 1 Loc. Effic & 1 \\
\hline 50 & & & 0.268 & 0.516 & 0.415 & 0.822 & & 1 Loc. Effic & 1 Loc. Effic \\
\hline 51 & & 0.277 & 0.558 & 0.155 & & & & & \\
\hline 52 & & & & & & 1 & 0.563 & 1 Loc. Effic & 0.29 \\
\hline 53 & $1 \mathrm{Loc}$ & oc. Effic & 0.246 & 0.490 & 9.2exp-05 & 0.434 & 0.518 & 0.082 & 0.182 \\
\hline 54 & & 1 & 0.602 & 0.411 & 0.109 & 0.637 & 0.509 & 1 & 0.551 \\
\hline 57 & & & & & & & & 0.052 & 0.223 \\
\hline 59 & & & & & & & & 1 & 1 Loc. Effic \\
\hline 60 & & & & & & & & 0.176 & 0.455 \\
\hline 61 & & & & & & & & 1 Loc. Effic & \\
\hline 63 & & & & & & & & 0.199 & 1 Loc. Effic \\
\hline 66 & & & & & & & & & 1 Loc. Effic \\
\hline Mean Cluster ( $G$ & & 0.631 & 0.483 & 0.383 & 0.369 & 0.712 & 0.655 & 0.669 & 0.731 \\
\hline St. Dev. Cluster & $(G)$ & 0.392 & 0.304 & 0.278 & 0.290 & 0.255 & 0.271 & 0.424 & 0.329 \\
\hline
\end{tabular}




\section{Concluding remarks}

Our paper contributes to filling the literature gap caused by the lack of DEA evidence on the efficiency of mutual fund managers. We reformulate the founding DPEI (Murthi et al., 1997) to develop a slacks-based manager efficiency index (SMEI) that may support efficiencybased decisions of fund companies regarding individual managers. Our SMEI model presents three main contributions to the appropriate evaluation of managers. First, our SMEI model evaluates the efficiency of managers in their entirety instead of focusing on individual mutual funds. Second, our SMEI model includes socio-demographic variables, such as managers' education and experience, to extend the mere consideration of portfolio results in the model. Third, according to Tone (2010), we propose our variation of the SMEI model to identify locally efficient managers in reference to the 'best practice' competitors with similar management characteristics.

We illustrate how the SMEI model works in a complete sample of individual managers in the Spanish mutual fund market. This illustration further examines the persistence of the efficiency scores resulting from the SMEI model and how the SMEI variables significantly influence the survivorship of individual managers. Finally, the local SMEI identifies locally efficient but globally inefficient managers according to the level of management specialisation. However, the results cast doubt on the general application of this local variant for small and excluding clusters. Further research should include not only SMEI extensions to deepen the understanding of managers' efficiency but also real applications to other mutual fund industries.

\section{Acknowledgements and funding}

We thank Juan Carlos Matallín and Belén Nieto for their insightful comments and suggestions. We thank three referees for their constructive comments. This work was supported by the Spanish government and European Union FEDER funds (ECO2013-45568-R) and the University of Zaragoza (JIUZ-2016-SOC-01). 


\section{References}

Agarwal, V., Daniel, N.D. \& Naik, N.Y., (2009). Role of managerial incentives and discretion in hedge fund performance. Journal of Finance, 64(5), 2221-2256.

Álvarez, M., García, J.P., \& Gouveia, O. (2016). The globalisation of banking: How is regulation affecting global banks? BBVA Research-Global Economic Watch, August 2016, $1-19$.

Andreu, L., Sarto, J.L. \& Vicente, L. (2014). Efficiency of the strategic style of pension funds: an application of the variants of the slacks-based measure in DEA. Journal of the Operational Research Society, 65(12), 1886-1895.

Andreu, L., \& Puetz, A. (2017). Choosing two business degrees versus choosing one: What does it tell about mutual fund managers' investment behavior? Journal of Business Research, 75, 138-146.

Babalos, V., Doumpos, M., Philippas, N., \& Zopounidis, C. (2012). Rating Mutual Funds Through an Integrated DEA-based Multicriteria Performance Model: Design and Information Content. Technical University of Crete, Financial Engineering Laboratory, Working Paper 2012.06.

Banker, R., Chen, J.Y., \& Klumpes, P. (2016). A Trade-Level DEA Model to Evaluate Relative Performance of Investment Fund Managers. European Journal of Operational Research, 255(3), 903-910.

Bär, M., Kempf, A., \& Ruenzi, S. (2011). Is a Team Different from the Sum of its Parts? Evidence from Mutual Fund Managers. Review of Finance, 15(2), 359-396.

Basso, A., \& Funari, S. (2001). A data envelopment analysis approach to measure the mutual fund performance. European Journal of Operational Research, 135(3), 477-492.

Basso, A., \& Funari, S. (2003). Measuring the performance of ethical funds: a DEA approach. Journal of the Operational Research Society, 54(5), 521-531.

Basso, A., \& Funari, S. (2017). The role of fund size in the performance of mutual funds assessed with DEA models. The European Journal of Finance, 23(6), 457-473.

Brandouy, O., Kerstens, K., \& Van de Woestyne, I. (2015). Frontier based vs. traditional mutual fund ratings: A first back testing analysis. European Journal of Operational Research, 242(1), 332-342.

Brealey, R.A., \& Kaplanis, E. (2001). Hedge funds and financial stability: An analysis of their factor exposures. International Finance, 4(2), 161-187.

Briec, W., \& Kerstens, K. (2009). Multi-horizon Markowitz portfolio performance appraisals: A general approach. Omega, The International Journal of Management Science,37(1), 50-62.

Briec, W., \& Kerstens, K. (2010). Portfolio selection in multidimensional general and partial moment space. Journal of Economic Dynamics and Control, 34(4), 636-656. 
Briec, W., Kerstens, K., \& Lesourd, J.B. (2004). Single-period Markowitz portfolio selection, performance gauging, and duality: A variation on the Luenberger shortage function. Journal of Optimization Theory and Applications, 120(1), 1-27.

Briec, W., Kerstens, K., \& Jokung, O. (2007). Mean-variance-skewness portfolio performance gauging: A general shortage function and dual approach. Management Science, 53(1), 135149.

Briec, W., Kerstens, K., \& Van de Woestyne, I. (2013). Portfolio selection with skewness: A comparison of methods and a generalized one fund result. European Journal of Operational Research, 230 (2), 412-421.

Carhart, M.M. (1997). On persistence in mutual fund performance. Journal of Finance, 52(1), 57-82.

Chang, K.P. (2004). Evaluating mutual fund performance: an application of minimum convex input requirement set approach. Computers and Operations Research, 31(6), 929-940.

Charnes, A., Cooper, W.W., \& Rhodes, E. (1978). Measuring the efficiency of decision making units. European Journal of Operational Research, 2(6), 429-444.

Charnes, A., Cooper, W.W., Golany, B., Seiford, L. \& Stutz, J. (1985). Foundations of data envelopment analysis for pareto-koopmans efficient empirical production functions. Journal of Econometrics, 30(1-2), 91-107.

Chen, H.L., Jegadeesh, N., \& Wermers, R. (2000). The value of active mutual fund management: An examination of the stockholdings and trades of fund managers. Journal of Financial and quantitative Analysis, 35(03), 343-368.

Choi, Y.K., \& Murthi, B.P.S. (2001). Relative performance evaluation of mutual funds: a nonparametric approach. Journal of Business Finance and Accounting, 28 (7/8), 853-876.

Clare, A., Motson, N., Sapuric, S. \& Todorovic, N. (2014). What impact does a change of fund manager have on mutual fund performance? International Review of Financial Analysis, 35, 167-177.

Cohen, D., Arnaud, L., \& Saint-Paul, G. (1997). French unemployment: A transatlantic perspective. Economic Policy, 25, 267-291.

Cooper, W.W., Seiford, L.M., \& Tone, K. (2007). Data Envelopment Analysis. A comprehensive text with models, applications, references and DEA-Solver Software. (2nd ed.). New York: Springer, (Chapter 13).

Cook, W.D., \& Seiford, L.M. (2009). Data envelopment analysis (DEA) - Thirty years on. European Journal of Operational Research, 192(1), 1-17.

Daraio, C., \& Simar, L. (2006). A robust nonparametric approach to evaluate and explain the performance of mutual funds. European Journal of Operational Research, 175(1), 516542. 
Díaz-Mendoza, A.C., López-Espinosa, G., \& Martínez, M.A. (2014). The efficiency of performance-based fee funds. European Financial Management, 20, 825-855.

Eling, M. (2006). Performance measurement of hedge funds using data envelopment analysis. Financial Markets and Portfolio Management, 20(4), 442-471.

Elton, E.J., Gruber, M.J., \& Blake, C.R. (2003). Incentive fees and mutual funds. Journal of Finance, 58(2), 779-804.

Elton, E.J., Gruber, M.J., Blake, C.R., Krasny, Y. \& Ozelge, S.O. (2010). The effect of holdings data frequency on conclusions about mutual fund behavior. Journal of Banking and Finance, 34(5), 912-922.

European Union Parliament (2014). Pension Schemes. Directorate General for Internal Policies. Policy Department A:Economic and Scientific Policy, PE536.281, August 2014, $1-70$.

Fama, E.F., \& French, K.R. (1993). Common risk factors in the returns on stocks and bonds. Journal of Financial Economics, 33(1), 3-56.

Fang, J., Kempf, A., \& Trapp, M. (2014). Fund manager allocation. Journal of Financial Economics, 111(3), 661-674.

Fung, W., \& Hsieh, D. (1997). Empirical characteristics of dynamic trading strategies: The case of hedge funds. Review of Financial Studies, 10(2), 275-302.

Galagedera, D.U.A., \& Silvapulle, P. (2002). Australian mutual fund performance appraisal using data envelopment analysis. Managerial Finance, 28(9), 60-73.

Golec, J.H., \& Starks, L.T. (2004). Performance fee contract change and mutual fund risk. Journal of Financial Economics, 73(1), 93-118.

Gregoriou, G.N., Sedzro, K., \& Zhu, J. (2005). Hedge fund performance appraisal using data envelopment analysis. European Journal of Operational Research, 164(2), 555-571.

Grinblatt, M. \& Titman, S. (1992). The persistence of mutual fund performance. Journal of Finance, 47(5), 1977-1984.

Haslem, J.A., \& Scheraga, C.A. (2003). Data envelopment analysis of Morningstar's large-cap mutual funds. Journal of Investing, 12(4), 41-48.

Hvide, H. K. (2003). Education and the allocation of talent. Journal of Labor Economics, 21, 945-977.

Inverco (2016). Statistics, December 2016. http://www.inverco.es/38/39/101/2016/12

Investment Company Institute (2017). Supplement: Worldwide Public Tables, Fourth Quarter 2016, Data in Euros. https://www.ici.org/research/stats/worldwide

Jensen, M.C. (1968). The Performance of Mutual Funds in the Period 1945-1964, Journal of Finance, 23(2), pp 389-416. 
Kerstens, K., Mounir, A., \& Van de Woestyne, I. (2011). Non-parametric frontier estimates of mutual fund performance using C- and L-moments: Some specification tests. Journal of Banking and Finance, 35(5), 1190-1201.

Kok, C., Mirza, H., Móré, C., \& Pancaro, C. (2016). Adapting bank business models: financial stability implications of greater reliance on fee and commission income. European Central Bank Financial Stability Review, November 2016, 147-157.

Kumar, U.D., Roy, A.B., Saranga, H., \& Singal, K. (2010). Analysis of hedge fund strategies using slack-based DEA models. Journal of the Operational Research Society, 61(12), 1746-1760.

Lamb, J., \& Tee, K.H. (2012a). Data envelopment analysis models of investment funds. European Journal of Operational Research, 216(3), 687-696.

Lamb, J.D., \& Tee, K.H. (2012b). Resampling DEA estimates of investment fund performance. European Journal of Operational Research, 223(3), 834-841.

Liu, J.S., Lu, L.Y.Y., Lu, W.M., \& Lin, B.J.Y. (2013). A survey of DEA applications. Omega, The International Journal of Management Science, 45(1), 893-902.

Lozano, S., \& Gutiérrez, E. (2008). TSD-consistent performance assessment of mutual funds. Journal of the Operational Research Society, 59(10), 1352-1362.

Ma, L., Tang, Y., \& Gomez, J.P. (2016). Portfolio manager compensation and mutual fund performance. SSRN Working Paper 2024027.

McMullen, P.R., \& Strong, R.A. (1998). Selection of mutual fund using data envelopment analysis. Journal of Business and Economic Studies, 4(1), 1-14.

Medeiros, M.T. (2010). Efficiency evaluation of the Portuguese pension funds management companies. Journal of International Financial Markets, Institutions and Money, 20(3), 259-266.

Morey, M.R., \& Morey, R.C. (1999). Mutual fund performance appraisals: a multi-horizon perspective with endogenous benchmarking. Omega, The International Journal of Management Science, 27(2), 241-58.

Morningstar (2017). Fundamentals for investors. https://advisor.mp.morningstar.com/resourceDownload?type=publicForms\&id=3f9dff3cf085-47a1-98ba-0bc008df9f25

Murthi, B.P.S., Choi, Y.K., \& Desai, P. (1997). Efficiency of mutual funds and portfolio measurement: a non-parametric approach. European Journal of Operational Research, 98(2), 408-418.

OECD (2014). Indicator A5: How does educational attainment affect participation in the labour market? Education at a glance 2014: OECD indicators. OECD Publishing. 
Pojarliev, M., \& Levich, R.M. (2010). Trades of the living dead: Style differences, style persistence and performance of currency fund managers. Journal of International Money and Finance, 29, 1752-1775.

Premachandra I., Powell, J.G., \& Shi, J. (1998). Measuring the relative efficiency of fund management strategies in New Zealand using a spreadsheet-based stochastic data envelopment analysis model. Omega, The International Journal of Management Science, 26(2), 319-331.

Premachandra, I.M., Zhu, J., Watson, J., \& Galagedera, D.U.A. (2012). Best-performing US mutual fund families from 1993 to 2008: evidence from a novel two-stage DEA model for efficiency decomposition. Journal of Banking and Finance, 36(12), 3302-3317.

Riddell, W. C., \& Song, X. (2011). The impact of education on unemployment incidence and re-employment success: Evidence from the U.S. labour market. Labour Economics, 18, 453-463.

Sánchez-González, C., Sarto, J.L., \& Vicente, L. (2017). The efficiency of mutual fund companies: Evidence from an innovative network SBM approach. Omega, The International Journal of Management Science, 71; 114-128.

Sharpe, W.F. (1966). Mutual fund performance. Journal of Business, 39(1), 119-138.

Spence, M. (1973). Job market signaling. The Quarterly Journal of Economics, 87, 355-374.

Tone, K. (2001). A slacks-based measure of efficiency in data envelopment analysis. European Journal of Operational Research, 130(3), 498-509.

Tone, K. (2010). Variations on the theme of slacks-based measure of efficiency in DEA. European Journal of Operational Research, 200(3), 901-907.

Wang, K., \& Huang, S. (2010). Using fast adaptive neural network classifier for mutual fund performance evaluation. Expert Systems with Applications, 37(8), 6007-6011.

Weiss, A. (1983). A sorting-cum-learning model of education. Journal of Political Economy, 91, 420-442.

Zambrana, R., \& Zapatero, F. (2017). A tale of two types: generalists vs. specialists in asset management. SSRN Working Paper 2672858. 


\section{Appendix A. SBM with undesirable outputs.}

The slacks-based measure with undesirable outputs is defined as follows. Let us consider a set of $n$ decision-making units (DMUs), where each DMU $j$ (for $j=1,2,3, \ldots, n$ ) has a set of 3 factors, namely, inputs, good outputs and undesirable (bad) outputs, as represented by the three vectors of $x \in R^{m}, y^{g} \in R^{s 1}$ and $y^{b} \in R^{s 2}$, respectively. The matrices $X$, $Y^{g}$ and $Y^{b}$ are defined as follows: $X=\left(x_{1}, \ldots, X_{n}\right) \in R^{m \times n}, Y^{g}=\left(y^{g} 1, \ldots, y^{g}\right) \in R^{s 1 \times n}$ and $Y^{b}=\left(y^{b}{ }_{1}, \ldots, y^{b}{ }_{n}\right) \in R^{s 2 \times n}$. We assume that $X>0, Y^{g}>0$ and $Y^{b}>0$. Under the hypothesis of constant returns to scale (CRS), $\lambda$ is a non-negative set of variables $\left(\lambda_{1, \ldots}, \lambda_{n}\right)$ that represents the intensity vector; $s^{-} \in R^{m}$ and $s^{b} \in R^{s 2}$ are the slack vectors that represent the non-negative sets of input and bad output excesses, respectively, while $s^{g} \in R^{s 1}$ is the slack vector that represents good output shortfalls. Therefore, the production possibility set $P$ is defined as

$$
P=\left\{\left(x, y^{g}, y^{b}\right) / x \geq \sum_{j=1}^{n} x_{j} \lambda_{j}, \quad y^{g} \leq \sum_{j=1}^{n} y_{j}^{g} \lambda_{j}, \quad y^{b} \geq \sum_{j=1}^{n} y_{j}^{b} \lambda_{j}, \quad \lambda_{j} \geq 0\right\}
$$

A target manager will be considered efficient in terms of Pareto-Koopmans when he/she has no slacks for any optimal solution, that is, when $S B M-$ Undesirable=1 according to the following model:

$$
S B M-\text { Undesirable }_{o}=\min \frac{1-(1 / m) \sum_{i=1}^{m} s_{i}^{-} / x_{i o}}{1+1 /(s 1+s 2)\left(\sum_{r=1}^{s 1} s_{r}^{g} / y_{r o}^{g}+\sum_{r=1}^{s 2} s_{r}^{b} / y_{r o}^{b}\right)}
$$

Subject to

$$
\sum_{j=1}^{n} x_{i j} \lambda_{j}+s_{i}^{-}=x_{i o} \quad \sum_{j=1}^{n} y_{r j}^{g} \lambda_{j}-s_{r}^{g}=y_{r o}^{g} \quad \sum_{j=1}^{n} y_{r j}^{b} \lambda_{j}+s_{r}^{b}=y_{r o}^{b} \quad \lambda_{j}, s_{i}^{-}, s_{r}^{g}, s_{r}^{b} \geq 0 \quad \forall j, i, r
$$

For the specific case that risk is considered to be an undesirable output but is jointly produced by return, then the weak disposability of outputs should hold. This weak disposability bounds the size of $P$ in the $y^{b}$ direction. Therefore, the new production possibility set $P$ should be defined as

$$
P=\left\{\left(x, y^{g}, y^{b}\right) / x \geq \sum_{j=1}^{n} x_{j} \lambda_{j}, \quad y^{g} \leq \sum_{j=1}^{n} y_{j}^{g} \lambda_{j}, \quad y^{b}=\sum_{j=1}^{n} y_{j}^{b} \lambda_{j}, \quad \lambda_{j} \geq 0\right\}
$$

This boundedness property involves that there are no slacks $s_{r}^{b}$ in the undesirable output constraint so the denominator of the objective function of Eq. (A2) will change to incorporate this non-separable condition of risk and return.

Furthermore, the aforementioned models can be generalised when certain bad outputs are not separable from the corresponding good outputs and certain inputs. For further details, see the NS-Overall model proposed in section 13.3 of Cooper et al. (2007). 


\section{Appendix B}

This appendix shows the distribution of the managers' efficiency scores during the sample period (2009-2016). The first column of the table shows a manager ID to maintain anonymity. Then, for each year, the table shows the SMEI scores (Eq. (4)) and the reference frontier.

\begin{tabular}{|c|c|c|c|c|c|c|c|c|c|c|c|c|c|c|c|c|}
\hline \multirow[b]{2}{*}{ Manager ID } & \multicolumn{2}{|c|}{2009} & \multicolumn{2}{|c|}{2010} & \multicolumn{2}{|c|}{2011} & \multicolumn{2}{|c|}{2012} & \multicolumn{2}{|c|}{2013} & \multicolumn{2}{|c|}{2014} & \multicolumn{2}{|c|}{2015} & \multicolumn{2}{|c|}{2016} \\
\hline & SMEI & Ref. & SMEI & Ref. & SMEI & Ref. & SMEI & Ref. & SMEI & Ref. & SMEI & Ref. & SMEI & Ref. & SMEI & Ref. \\
\hline 1 & 0.430 & 2,4 & 1 & 1 & 1 & 1 & 1 & 1 & 1 & 1 & 1 & 1 & - & - & - & - \\
\hline 2 & 1 & 2 & 1 & 2 & 1 & 2 & - & - & - & - & - & - & - & - & - & - \\
\hline 3 & 0.128 & 39 & 0.021 & 7 & 0.029 & 7 & - & - & 0.124 & 7,35 & 0.145 & 7 & 0.036 & 39 & 0.025 & 39 \\
\hline 4 & 1 & 4 & 0.184 & 7 & 0.074 & 7 & 0.076 & 7 & 0.146 & 7,35 & 0.231 & 7 & 0.031 & 39 & 0.145 & 39 \\
\hline 5 & 1 & 5 & 0.117 & 7,39 & 0.079 & 7 & - & - & - & - & - & - & - & - & - & - \\
\hline 6 & - & - & - & - & - & - & 0.027 & 7 & 0.053 & 7,35 & 0.542 & 7 & - & - & - & - \\
\hline 7 & - & - & 1 & 7,39 & 1 & 7 & 1 & 7 & 1 & 7 & 1 & 7 & 0.337 & 39 & 1 & 7 \\
\hline 8 & 0.077 & 39 & 0.035 & 7 & 0.030 & 7 & 0.033 & 7 & 0.000 & 7,27 & 0.000 & 7,27 & 0.000 & 39,56 & 0.000 & 68 \\
\hline 9 & - & - & 0.025 & 7,49 & 0.028 & 7 & 0.035 & 7,46 & 0.031 & 7,35 & 0.033 & 7 & 0.009 & 39 & 0.009 & 39 \\
\hline 10 & 0.420 & $2,4,39$ & 0.139 & 7 & 0.203 & 7 & 0.064 & 7 & 0.074 & 7,35 & 0.253 & 7 & 0.120 & 39 & 0.135 & 7,39 \\
\hline 11 & 1 & 11 & 0.025 & 7,48 & 0.323 & 7,48 & - & - & - & - & - & - & - & - & - & - \\
\hline 12 & 0.128 & $2,4,42$ & 0.075 & 7 & 0.108 & 7 & 0.100 & 7 & 0.109 & 35 & 0.299 & 7,31 & 1 & 12 & 1 & 12 \\
\hline 13 & 0.128 & $4,39,42$ & 0.043 & 7 & 0.034 & 7 & 0.043 & 7 & 0.039 & 35 & 0.096 & 7 & 0.291 & 29 & 0.155 & 56 \\
\hline 14 & 1 & 14 & 0.172 & 7,48 & 0.152 & 7 & 0.168 & 7 & 1 & 14 & 0.361 & $1,23,29$ & 0.244 & 29 & 0.341 & 56 \\
\hline 15 & 0.553 & 2,14 & 0.067 & 7 & 0.053 & 7 & 0.027 & 7 & 0.047 & 29,35 & 0.020 & 7 & - & - & - & - \\
\hline 16 & - & - & 0.006 & 7 & 0.007 & 7 & 0.007 & 7 & 0.063 & 7,35 & 0.272 & 7 & 0.131 & 39 & 0.116 & 39 \\
\hline 17 & - & - & 0.053 & 7 & 0.056 & 7 & 0.045 & 7 & - & - & - & - & - & - & - & - \\
\hline 18 & 0.063 & 2 & 0.018 & 7 & 0.021 & 7 & 0.010 & 7 & 0.015 & 35 & 0.051 & 29 & 0.054 & 29 & 0.099 & 56 \\
\hline 19 & 0.613 & 4,5,39 & 0.000 & 39 & 0.095 & 7 & 0.059 & 7 & 0.372 & 7,35 & 0.385 & 7 & 0.329 & 39,56 & 0.311 & 56,68 \\
\hline 20 & 0.044 & $2,4,14,42$ & 0.005 & 7 & 0.005 & 7 & - & - & - & - & - & - & - & - & - & - \\
\hline 21 & 0.237 & 11,42 & 0.036 & 7 & - & - & - & - & - & - & - & - & - & - & - & - \\
\hline 22 & - & - & 0.156 & 7 & 0.224 & 7 & 0.133 & 7 & 1 & 22 & 0.446 & 7,27 & - & - & - & - \\
\hline 23 & - & - & - & - & - & - & - & - & - & - & 1 & 23 & 0.025 & 29,54 & 0.275 & 56 \\
\hline 24 & - & - & 0.066 & 7 & - & - & - & - & - & - & - & - & - & - & - & - \\
\hline 25 & 1 & 25 & 0.017 & 7,49 & 0.023 & 7 & - & - & - & - & - & - & - & - & - & - \\
\hline 26 & 0.031 & 39 & 0.008 & 7 & 0.011 & 7 & - & - & - & - & - & - & - & - & - & - \\
\hline 27 & - & - & 0.115 & 7 & 0.114 & 7 & 0.107 & 7 & 1 & 27 & 1 & 27 & 1 & 27 & 1 & 27 \\
\hline 28 & 0.046 & 39,42 & 0.004 & 7 & 0.011 & 7 & 0.014 & 7 & 0.076 & 7,35 & 0.109 & 7 & 0.037 & 39 & 0.018 & 39 \\
\hline 29 & 0.079 & 39 & 0.022 & 7 & 0.028 & 7 & 0.034 & 7 & 1 & 29 & 1 & 29 & 1 & 29 & 1 & 29 \\
\hline 30 & - & - & - & - & - & - & - & - & 1 & 30 & 1 & 30 & 0.045 & 39,56 & - & - \\
\hline 31 & 0.010 & 39,42 & 0.009 & 7 & 0.022 & 7 & 0.027 & 7 & 0.161 & 35 & 1 & 31 & - & - & - & - \\
\hline 32 & 0.362 & $4,11,14,42$ & 0.069 & 7 & 0.088 & 7 & 0.087 & 7 & 0.071 & 35 & 0.067 & 7 & - & - & - & - \\
\hline 33 & 0.127 & $11,25,39,54$ & - & - & - & - & - & - & - & - & - & - & - & - & 0.017 & 39 \\
\hline 34 & - & - & - & - & - & - & - & - & - & - & 0.133 & 7,37 & - & - & - & - \\
\hline
\end{tabular}


Appendix B (Continued)

\begin{tabular}{|c|c|c|c|c|c|c|c|c|c|c|c|c|c|c|c|c|}
\hline \multirow[b]{2}{*}{ Manager ID } & \multicolumn{2}{|c|}{2009} & \multicolumn{2}{|c|}{2010} & \multicolumn{2}{|c|}{2011} & \multicolumn{2}{|c|}{2012} & \multicolumn{2}{|c|}{2013} & \multicolumn{2}{|c|}{2014} & \multicolumn{2}{|c|}{2015} & \multicolumn{2}{|c|}{2016} \\
\hline & SMEI & Ref. & SMEI & Ref. & SMEI & Ref. & SMEI & Ref. & SMEI & Ref. & SMEI & Ref. & SMEI & Ref. & SMEI & Ref. \\
\hline 35 & 0.229 & $4,39,42$ & 0.066 & 7 & 0.070 & 7 & - & - & 1 & 35 & - & - & - & - & - & - \\
\hline 36 & - & - & 0.100 & $7,48,49$ & 0.000 & 7 & 1 & 36 & - & - & - & - & - & - & - & - \\
\hline 37 & - & - & - & - & - & - & - & - & - & - & 1 & 37 & 1 & 37 & 0.481 & 56 \\
\hline 38 & - & - & - & - & - & - & - & - & - & - & 0.323 & 37 & - & - & - & - \\
\hline 39 & 1 & 39 & 1 & 39 & 0.412 & 7 & 1 & 39 & 1 & 39 & 1 & 39 & 1 & 39 & 1 & 39 \\
\hline 40 & 0.000 & 4 & - & - & - & - & - & - & - & - & - & - & - & - & - & - \\
\hline 41 & - & - & - & - & - & - & 1 & 41 & 1 & 41 & 0.282 & 37 & - & - & - & - \\
\hline 42 & 1 & 42 & 0.196 & 7 & 0.141 & 7 & - & - & - & - & - & - & - & - & - & - \\
\hline 43 & - & - & - & - & - & - & - & - & 0.102 & 7,19 & 0.083 & 7 & - & - & - & - \\
\hline 44 & - & - & 0.124 & 7,49 & 0.039 & 7 & 0.169 & $7,36,46$ & - & - & - & - & - & - & - & - \\
\hline 45 & - & - & - & - & 0.029 & 7 & 0.072 & 7,46 & 0.258 & 7,19 & 0.388 & 7 & - & - & - & - \\
\hline 46 & - & - & - & - & - & - & 1 & 46 & 0.241 & 7,30,52 & 0.113 & 7,37 & 0.191 & $37,39,56$ & 0.053 & 39,68 \\
\hline 47 & - & - & 0.022 & 7,49 & 0.011 & 7 & 0.012 & 7 & 0.021 & 7,19 & 0.014 & 7 & 0.003 & 39 & 0.005 & 39,68 \\
\hline 48 & - & - & 1 & 48 & 1 & 48 & - & - & - & - & - & - & - & - & - & - \\
\hline 49 & - & - & 1 & 49 & 0.035 & 7 & 0.037 & 7,46 & 0.033 & 35 & 0.042 & 7 & 0.001 & 39,56 & 1 & \\
\hline 50 & - & - & 0.059 & 7 & 0.067 & 7 & 0.158 & 7 & 0.743 & 7,19 & - & - & 0.807 & 29,56 & 0.526 & 39,68 \\
\hline 51 & 0.163 & 14,42 & 0.027 & 7 & 0.079 & 7 & - & - & - & - & - & - & - & - & - & - \\
\hline 52 & - & - & - & - & - & - & - & - & 1 & 52 & 0.230 & 7 & 0.076 & 39 & 0.074 & 39 \\
\hline 53 & 0.230 & $4,11,39,42$ & 0.032 & 7 & 0.025 & 7 & 0.000 & 7,46 & 0.070 & 7,35 & 0.126 & 7 & 0.022 & 39 & 0.022 & 39 \\
\hline 54 & 1 & 54 & 0.019 & 7 & 0.020 & 7 & 0.028 & 7,46 & 0.090 & 7,19 & 0.070 & 7 & 1 & 54 & 0.047 & 39 \\
\hline 55 & & & & & & & & & & & & & 0.013 & 39,56 & 0.014 & 39,68 \\
\hline 56 & & & & & & & & & & & & & 1 & 56 & 1 & 56 \\
\hline 57 & & & & & & & & & & & & & 0.015 & 39 & 0.013 & 39 \\
\hline 58 & & & & & & & & & & & & & 1 & 58 & 0.191 & 68 \\
\hline 59 & & & & & & & & & & & & & 1 & 59 & 0.277 & 68 \\
\hline 60 & & & & & & & & & & & & & 0.050 & 29 & 0.034 & 39,56 \\
\hline 61 & & & & & & & & & & & & & 0.184 & 39,59 & - & - \\
\hline 62 & & & & & & & & & & & & & 0.053 & $39,56,59$ & 0.196 & 56 \\
\hline 63 & & & & & & & & & & & & & 0.069 & 29 & 0.127 & 56 \\
\hline 64 & & & & & & & & & & & & & - & - & 0.024 & 39 \\
\hline 65 & & & & & & & & & & & & & - & - & 0.052 & 39,68 \\
\hline 66 & & & & & & & & & & & & & - & - & 0.008 & 56 \\
\hline 67 & & & & & & & & & & & & & - & - & 0.090 & 39,68 \\
\hline 68 & & & & & & & & & & & & & - & - & 1 & 68 \\
\hline
\end{tabular}


Appendix C

This appendix shows the efficiency ranking for each individual manager during the sample period (2009-2016).

\begin{tabular}{|c|c|c|c|c|c|c|c|c|c|c|c|c|c|c|c|c|c|}
\hline Manager ID & 2009 & 2010 & 2011 & 2012 & 2013 & 2014 & 2015 & 2016 & Manager ID & 2009 & 2010 & 2011 & 2012 & 2013 & 2014 & 2015 & 2016 \\
\hline 1 & 12 & 1 & 1 & 1 & 1 & 1 & - & - & 35 & 17 & 19 & 18 & - & 1 & - & - & - \\
\hline 2 & 1 & 1 & 1 & - & - & - & - & - & 36 & - & 15 & 40 & 1 & - & - & - & - \\
\hline 3 & 19 & 32 & 27 & - & 18 & 22 & 26 & 29 & 37 & - & - & - & - & - & 1 & 1 & 10 \\
\hline 4 & 1 & 8 & 17 & 14 & 17 & 20 & 27 & 18 & 38 & - & - & - & - & - & 15 & - & - \\
\hline 5 & 1 & 13 & 15 & - & - & - & - & - & 39 & 1 & 1 & 5 & 1 & 1 & 1 & 1 & 1 \\
\hline 6 & - & - & - & 26 & 27 & 10 & - & - & 40 & 30 & - & - & - & - & - & - & - \\
\hline 7 & - & 1 & 1 & 1 & 1 & 1 & 11 & 1 & 41 & - & - & - & 1 & 1 & 17 & - & - \\
\hline 8 & 24 & 25 & 25 & 23 & 34 & 36 & 35 & 39 & 42 & 1 & 7 & 10 & - & - & - & - & - \\
\hline 9 & - & 28 & 28 & 21 & 31 & 33 & 32 & 36 & 43 & - & - & - & - & 20 & 28 & - & - \\
\hline 10 & 13 & 11 & 8 & 16 & 23 & 19 & 18 & 19 & 44 & - & 12 & 22 & 7 & - & - & - & - \\
\hline 11 & 1 & 29 & 6 & - & - & - & - & - & 45 & - & - & 26 & 15 & 14 & 12 & - & - \\
\hline 12 & 20 & 16 & 12 & 12 & 19 & 16 & 1 & 1 & 46 & - & - & - & 1 & 15 & 25 & 15 & 25 \\
\hline 13 & 21 & 23 & 24 & 19 & 29 & 27 & 13 & 17 & 47 & - & 31 & 35 & 29 & 32 & 35 & 33 & 38 \\
\hline 14 & 1 & 9 & 9 & 8 & 1 & 14 & 14 & 11 & 48 & - & 1 & 1 & - & - & - & - & - \\
\hline 15 & 11 & 18 & 21 & 27 & 28 & 34 & - & - & 49 & - & 1 & 23 & 20 & 30 & 32 & 34 & 1 \\
\hline 16 & - & 38 & 38 & 31 & 26 & 18 & 17 & 21 & 50 & - & 21 & 19 & 9 & 12 & - & 10 & 9 \\
\hline 17 & - & 22 & 20 & 18 & - & - & - & - & 51 & 18 & 27 & 16 & - & - & - & - & - \\
\hline 18 & 25 & 34 & 33 & 30 & 33 & 31 & 21 & 22 & 52 & - & - & - & - & 1 & 21 & 19 & 24 \\
\hline 19 & 10 & 41 & 13 & 17 & 13 & 13 & 12 & 12 & 53 & 16 & 26 & 30 & 32 & 25 & 24 & 29 & 31 \\
\hline 20 & 27 & 39 & 39 & - & - & - & - & - & 54 & 1 & 33 & 34 & 24 & 21 & 29 & 1 & 27 \\
\hline 21 & 15 & 24 & - & - & - & - & - & - & 55 & & & & & & & 31 & 34 \\
\hline 22 & - & 10 & 7 & 10 & 1 & 11 & - & - & 56 & & & & & & & 1 & 1 \\
\hline 23 & - & - & - & - & - & 1 & 28 & 14 & 57 & & & & & & & 30 & 35 \\
\hline 24 & - & 20 & - & - & - & - & - & - & 58 & & & & & & & 1 & 16 \\
\hline 25 & 1 & 35 & 31 & - & - & - & - & - & 59 & & & & & & & 1 & 13 \\
\hline 26 & 28 & 37 & 37 & - & - & - & - & - & 60 & & & & & & & 23 & 28 \\
\hline 27 & - & 14 & 11 & 11 & 1 & 1 & 1 & 1 & 61 & & & & & & & 16 & - \\
\hline 28 & 26 & 40 & 36 & 28 & 22 & 26 & 25 & 32 & 62 & & & & & & & 22 & 15 \\
\hline 29 & 23 & 30 & 29 & 22 & 1 & 1 & 1 & 1 & 63 & & & & & & & 20 & 20 \\
\hline 30 & - & - & - & - & 1 & 1 & 24 & - & 64 & & & & & & & & 30 \\
\hline 31 & 29 & 36 & 32 & 25 & 16 & 1 & - & - & 65 & & & & & & & & 26 \\
\hline 32 & 14 & 17 & 14 & 13 & 24 & 30 & - & - & 66 & & & & & & & & 37 \\
\hline 33 & 22 & - & - & - & - & - & - & 33 & 67 & & & & & & & & 23 \\
\hline 34 & - & - & - & - & - & 23 & - & - & 68 & & & & & & & & 1 \\
\hline
\end{tabular}


